\title{
Alternative Use of Roundabout AS StORM WATER DETENTION POND
}

D. Y. S. Mah ${ }^{1}$ and T. Y. Ho ${ }^{1}$.

${ }^{1}$ Department of Civil Engineering, Faculty of Engineering, Universiti Malaysia Sarawak, 93000, Kota Samarahan, Sarawak, Malaysia

Date received: 04/12/2016, Date accepted: 15/04/2017

Corresponding author's email: ysmah@unimas.my

\begin{abstract}
This study explores the concept of utilising roundabout as a component of the urban stormwater system. The research team has developed a drainage model to incorporate a roundabout as dry detention pond. In addition, the model is used to determine the effectiveness of such design by applying the concept virtually on a real-world roundabout at the southeast of UniGarden, a housing estate situated about $17 \mathrm{~km}$ from Kuching City of Sarawak. Computer representations of the existing drainage system and roundabout dry detention pond are built using the USEPA SWMM software. The modelling effort shows that the open space provided by a large roundabout is capable of achieving the maximum attenuation of storm flows and is able to hold $100 \%$ of runoff from 100-year storm. As empty spaces are increasingly hard to come by in urban areas; therefore, using an open space in a roundabout for dry detention pond is a good example of an innovative drainage system.
\end{abstract}

Keywords: Dry detention pond, flood infrastructure, runoff, SW

\subsection{INTRODUCTION}

Roundabout is a form of road intersection with a round island in the middle; it allows traffic to move in a circular and continuous flow [1]. Kuching city is famous for its large-sized and large number of roundabouts. As depicted in Figure 1, there are nine roundabouts in such a small part of Kuching. The River Kuap marks the administrative boundary between Kuching and Samarahan Divisions.

For aesthetic purposes, the middle portion of roundabout islands is usually decorated with hard and/or soft landscapes [2]. The landscape elements are deemed, among others, to represent local heritage or identity [3], promote visual effect [4], and enhance urban ecological connectivity [5]. In this paper, the concept of utilising roundabout as a component of the urban stormwater system is explored. The roundabout chosen is located at the southeast of UniGarden, and at km-17 of the Kuching-Samarahan Expressway. 


\section{Journal of Civil Engineering, Science and Technology}

Volume 8, Issue 1, April 2017
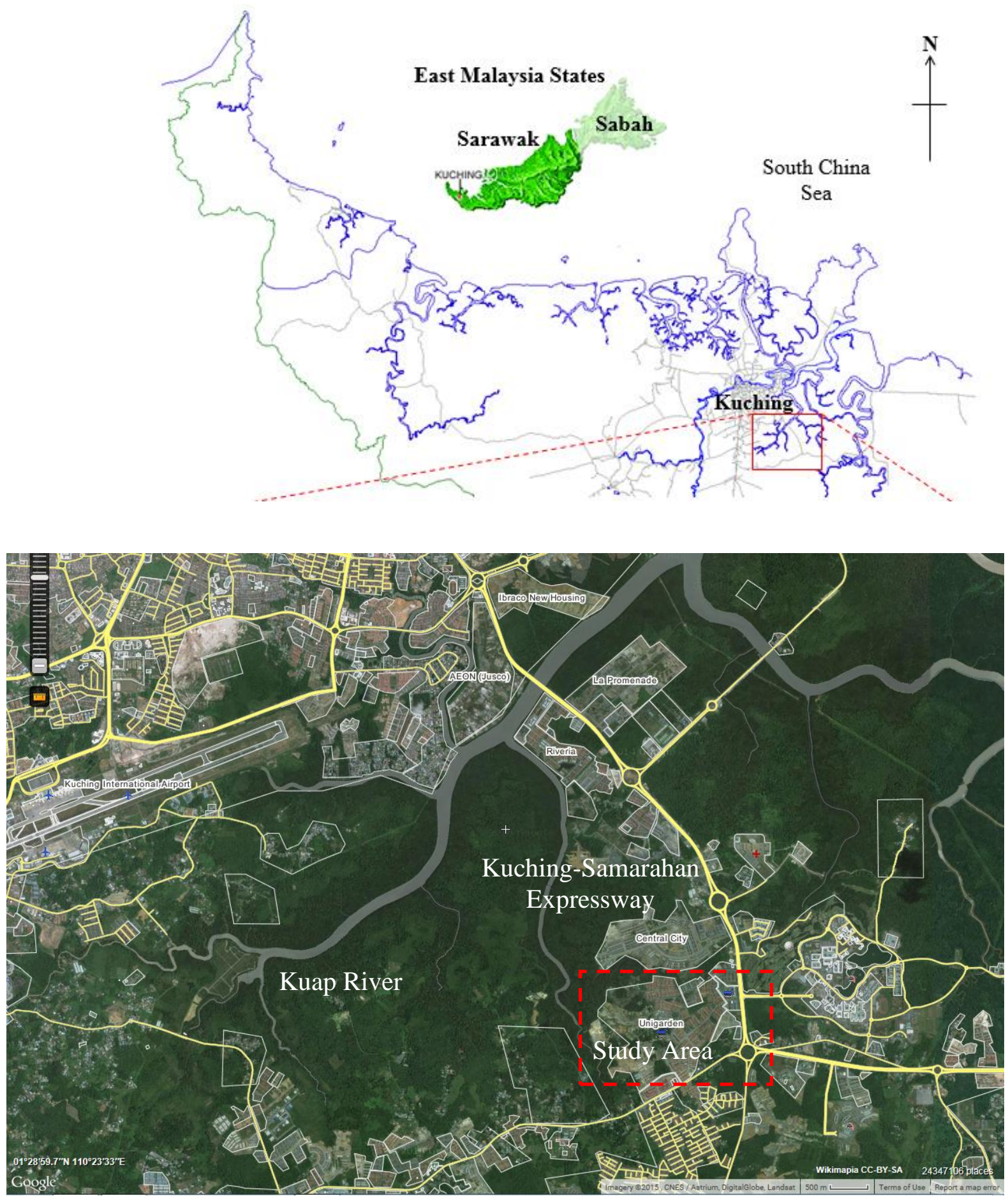

Figure 1: Locality of Study Area (http://www.wikimapia.org)

\subsection{RATIONALE OF THE STUDY}

UniGarden is a housing estate in Kota Samarahan. Before this residential development, the piece of land was a marshland flourishing with wetland plants. There were no flood problems in the surrounding areas prior to the development of UniGarden. The massive land filling in preparation for the housing development had drained the marshes significantly. As such, the water absorbing ability of this former wetland was drastically reduced.

After the housing estate was completed, the area experiences flash floods quite frequently, more than 


\section{Journal of Civil Engineering, Science and Technology}

Volume 8, Issue 1, April 2017

three times thus far. The most recent flash flood occurred on 18 January 2015, as depicted in Figure 2. The stormwater drainage of the housing estate was designed to flow eastward and eventually being drained to an earth drain beside the expressway serving as a receiving end of surface runoff from the housing estate. Flash floods were observed to have runoff accumulated along the earth drain and spilled over the bank to the nearby roads and commercial shoplots. No flooding was observed within the housing estate.

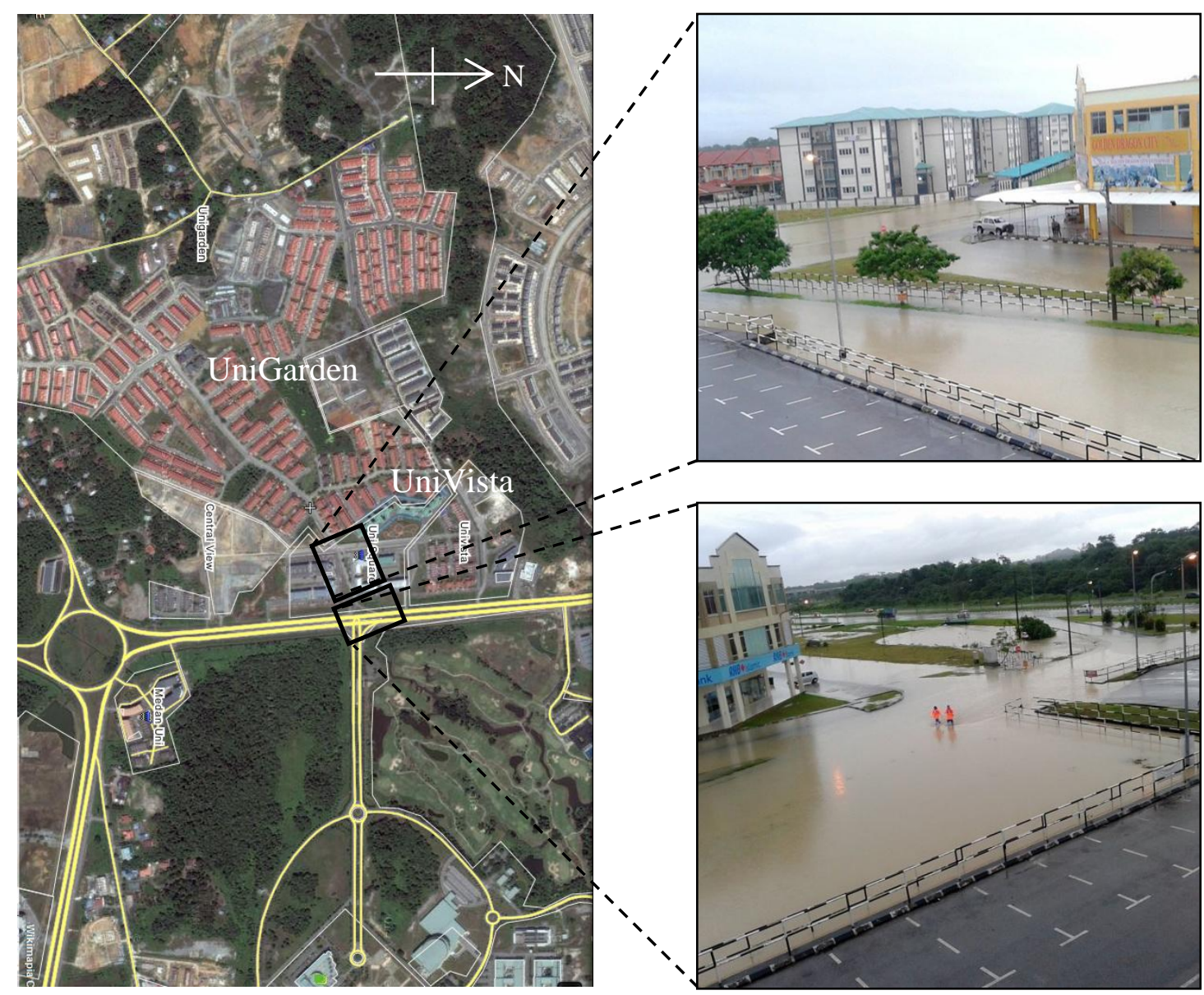

Figure 2. Flash Flood in UniGarden in January 2015 (http://www.wikimapia.org)

Obviously, the existing earth drain is unable to cope with a large volume of water when there is a prolonged period of rain; this was the case in the January 2015 event when there were four days of nonstop rain. Due to the rapid development in the vicinity of UniGarden (especially the different phases of residential housing projects of UniGarden and UniVista), the area of impervious land surfaces has increased many folds, hence contributing to the loss of natural stormwater storage the former marshland could provide. This water needs a place to go to.

Not far away, a big roundabout with a diameter of about $200 \mathrm{~m}$ is lying idly as grassland. The surface area of the round traffic island is approximately $31,000 \mathrm{~m}^{2}$, which is the largest open space readily available in the area. Hence, converting this round island to a stormwater detention pond would serve the goals of good land management and stormwater management practices simultaneously. 


\section{Journal of Civil Engineering, Science and Technology}

Volume 8, Issue 1, April 2017

It is the intention of this project to redirect the surface runoff from UniGarden $600 \mathrm{~m}$ down the road to the mentioned roundabout. The sheer size of the roundabout could be harnessed to accommodate a surge of floodwater, thus lowering the congestion of water flow in the drainage system.

\subsection{STORMWATER DETENTION POND}

Stormwater detention pond is a manmade structure designed to receive surface runoff and provide a momentary storage for runoff during rainy days. In other words, it remains dry during normal weather and easily blends in with the existing landscape. As such, it has also earned the name "dry detention pond" [6]. The empty space of a dry detention pond can be used as green space, wild habitat, or recreational ground when it is in a dry condition.

Urban Storm Water Management Manual for Malaysia or Manual Saliran Mesra Alam (MSMA) has named this structure as detention basin in Chapter 7 or infiltration basin in Chapter 8 [7]. It functions to minimise the peak flow rate and energy of stormwater discharges [8]. In cases where natural infiltration processes are allowed, it removes a large portion of suspended solids of up to $90 \%$, even though the efficiency of pollutant removal is lower [9].

Dry detention pond is not as common as wet pond in Malaysia. The two are quite easily distinguishable as wet ponds are always filled with water. For a large scale dry detention pond, storm volumes of up to 100 -year events are needed and a maximum of 48 hours detention time is suggested. Such a design is rarely seen in Malaysia and one example is available in Kota Damansara, Selangor [10]-[11]. Designs of smaller scales such as those for 2-, 5- or 10-year events are more common, as they are widely promoted by the River Engineering and Urban Drainage Research Centre (REDAC) of Universiti Sains Malaysia as an essential component of BIOECODS [12]; the mentioned university campus itself was a pilot study of the system. An example was reported in [13].

Using the open space in a roundabout for dry detention pond is a good example of an innovative drainage system [14]. A cursory survey of literature reveals a past study of University of Abertay Dundee, which contains creative use of a roundabout; the drainage system incorporates a roundabout dry detention pond as shown in Figure 3. The Dunfermline Eastern Expansion (DEX) is the site of this particular study, which is also the largest area that applies sustainable drainage method in the United Kingdom [15]. DEX is a predominantly greenery field with an area of 550 ha $\left(5.5 \mathrm{~km}^{2}\right)$. Therefore, a large scale dry pond was constructed to achieve a maximum attenuation of storm flows, which can hold up to $90 \%$ of runoff from the storms. Other than DEX, the research team of this study has not been able to find similar applications of roundabouts. 


\section{Journal of Civil Engineering, Science and Technology}

Volume 8, Issue 1, April 2017

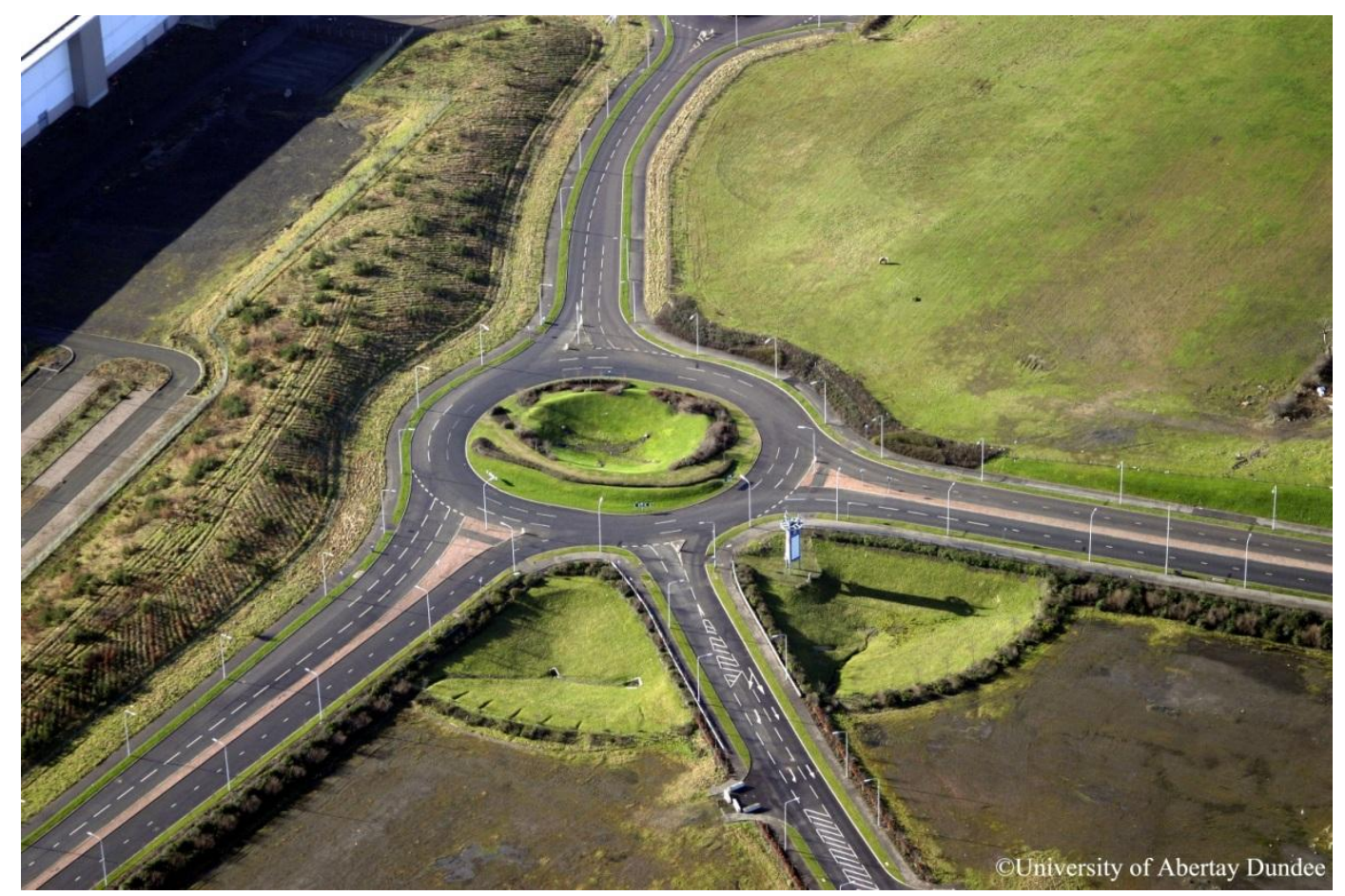

Figure 3. DEX Roundabout Dry Detention Pond (http://sudsnet.abertay.ac.uk)

\subsection{METHODOLOGY}

In this paper, roundabout and dry detention pond are integrated as a stormwater system. Due to the shape of the roundabout, the dry detention pond is proposed to be in the form of a cylindrical-shaped pond (Figure 4). The inlet level is designed to be at a higher level from the ground to prevent back flooding. An outlet is necessary to act as a "safety valve" to drain off excess water in order to avoid overflowing. The drains connected to the inlet and outlet should be constructed as culverts under the road.

A certain area in the roundabout island is reserved for future purposes such as facilitation of maintenance works and other traffic activities. Hence, the area earmarked for the dry detention pond is about $20,100 \mathrm{~m}^{2}$. In order to meet the design requirements of retaining all runoff for storms of up to 100-year event in the vicinity of UniGarden, parameter values such as depth, area, volume and side slope of the pond must be sufficiently large to achieve the objective. 


\section{Journal of Civil Engineering, Science and Technology}

Volume 8, Issue 1, April 2017

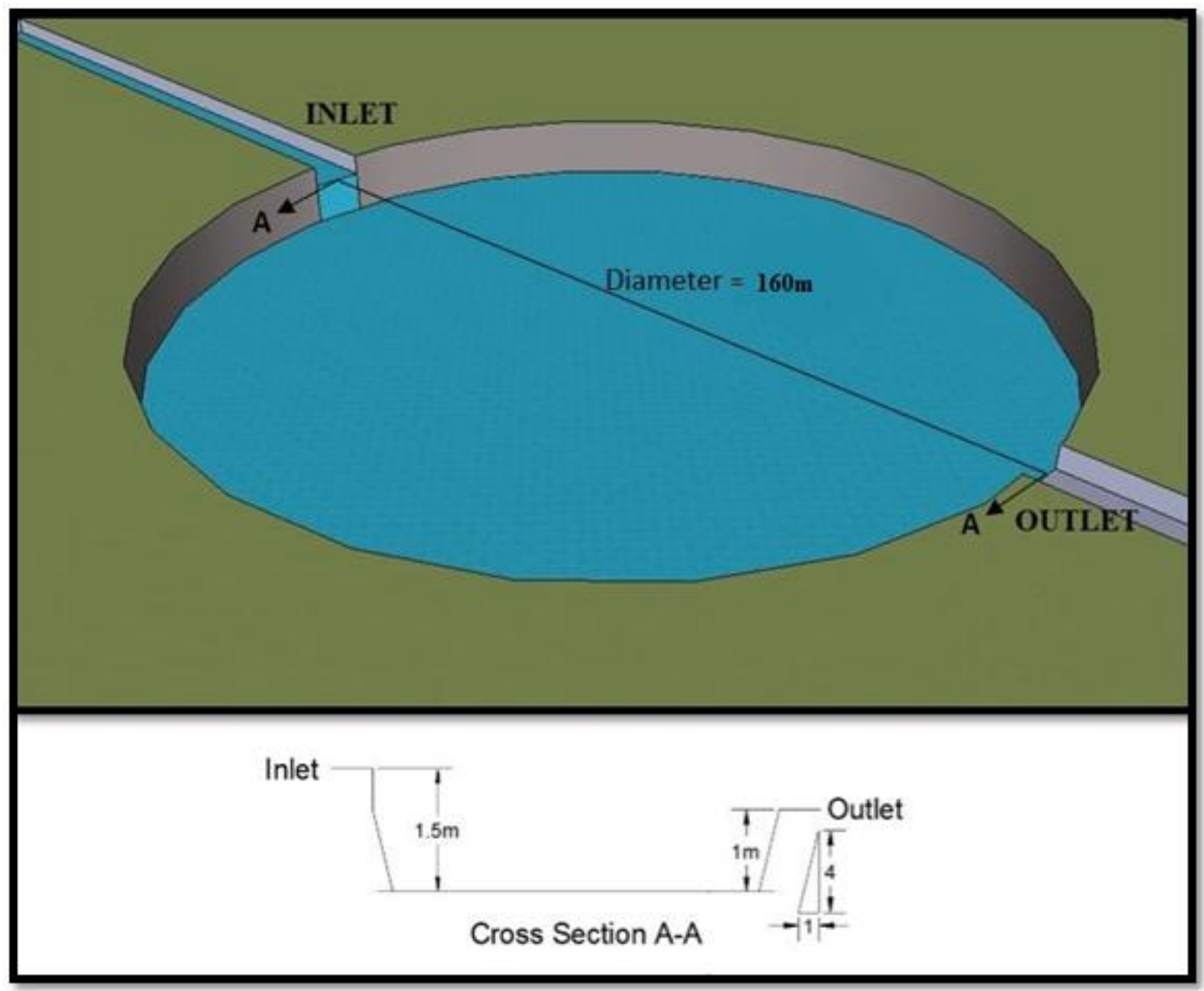

Figure 4. Dimension of the Proposed Roundabout Dry Detention Pond

Safety is one of the important factors that should be considered in designing the dry detention pond. The risk of a vehicle landing up in the dry detention pond is there since it is built within the roundabout. To make it less hazardous for the public, the recommended depth of the pond should not be more than be $1.5 \mathrm{~m}$ according to MSMA requirements. The authors have decided to set the depth of the pond at $1 \mathrm{~m}$, which is within the recommended range.

The steeper the slope of dry detention pond is, the higher the risk of accidents occurring. A safe limit of the slope is for it not to be steeper than $1(\mathrm{~V}): 4(\mathrm{H})$; otherwise, the dry detention pond should be fenced in. Hence, the steepness of the side slope chosen for this proposed pond is $1(\mathrm{~V}): 4(\mathrm{H})$. The volume of water that can be contained in this pond is estimated at $20,043 \mathrm{~m}^{3}$.

The drainage model is built to test the roundabout dry detention pond's effectiveness by using USEPA Storm Water Management Model (SWMM) software (see Figure 5). SWMM is widely applied in the planning, analysis and design related to urban drainage systems. It is a dynamic rainfall-runoff model capable of simulating the movement of surface runoff through a system that consists of pipes, channels, pumps, regulators, storage devices and treatment devices to the receiving water [16].

Rainwater falls on roofs, roads and land surfaces. These rainwater-receiving objects are collectively termed catchments, and the rainwater received contributes to the surface runoff. This running water 


\section{Journal of Civil Engineering, Science and Technology}

Volume 8, Issue 1, April 2017

flows into the concrete drains within the housing estate. Eventually, the network of concrete drains end at an earth drain before the water is drained to a nearby small stream.

The fact that no flooding within the UniGarden suggests that the minor drainage system is adequate. Field observations have found that some stretches of the drains are over $1 \mathrm{~m}$ deep. Therefore, the dimensions of existing minor drains and their slopes are carefully surveyed and input to the model. Even the size of the flood-prone earth drain is taken as it is to check on whether the compensation of the loss of natural storage (highlighted in Section 2) with a manmade structure could solve the flash flooding caused by the earth drain. Abbreviations used for labelling various items in the model simulation are R, S, C, J, OF, OL and DDP, which represent rain gage, subcatchment, conduit, junction, outfall, outlet and dry detention pond respectively.

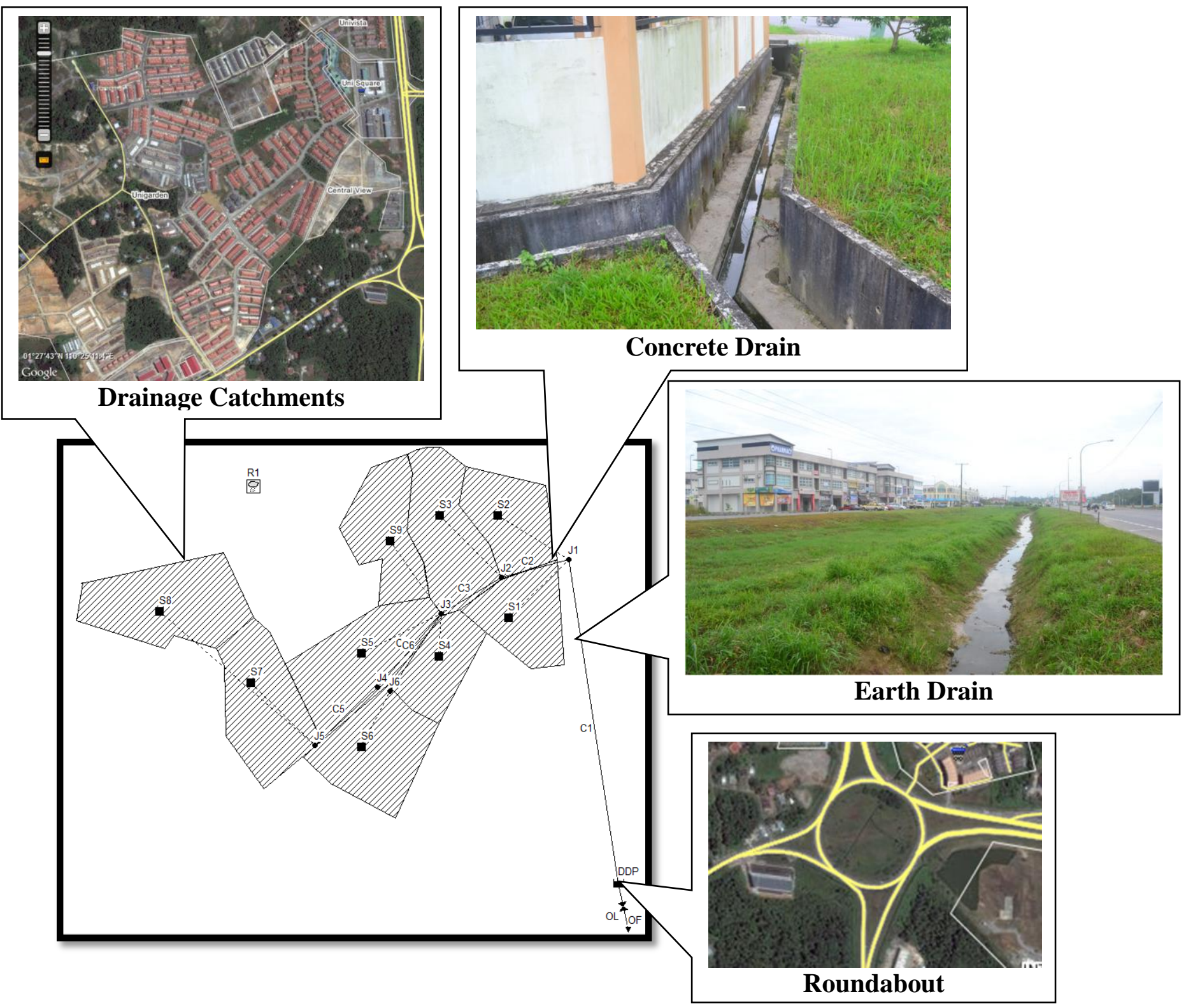

Figure 5. SWMM Model of the Existing Drainage System with Roundabout Dry Detention Pond 


\section{Journal of Civil Engineering, Science and Technology}

Volume 8, Issue 1, April 2017

By using SWMM, surface runoff produced in UniGarden is traced through the existing drains until the water reaches an exit point, which is termed as an outfall in SWMM. Two scenarios are presented here. Scenario 1 models the existing drainage system subject to a 100-year storm event, in which the model ends without entering the roundabout. Scenario 2 models the same drainage system but with the addition of a dry detention pond. The difference between the two models is that Scenario 1 ends with an outfall; while in Scenario 2, a dry detention pond and an outlet are added before the outfall.

\subsection{RESULTS AND DISCUSSION}

Flow at outfall in Scenario 1 is compared with the flow at the dry detention pond in Scenario 2. In Figure 6, the peak flow at outfall in Scenario 1 is estimated to be $6.27 \mathrm{~m}^{3} / \mathrm{s}$ while the peak flow at the dry detention pond for in Scenario 2 is $5.53 \mathrm{~m}^{3} / \mathrm{s}$. The difference is $0.74 \mathrm{~m}^{3} / \mathrm{s}$. This $10 \%$ reduction does not seem to be a significant reduction but the result shows that runoff from UniGarden is $100 \%$ contained in the dry detention pond. To put it in another word, the surface runoff that could have caused flooding by spilling out of the earth drain is possible to be stored within the roundabout. The existing earth drain is able to deliver the surface runoff to the roundabout. The sheer size of the dry detention pond that receiving the runoff allows the spreading of running water in the pond, and thus lowering the peak flow value. The hydrograph in the dry detention pond recedes because of ponding effect within the roundabout dry detention pond.

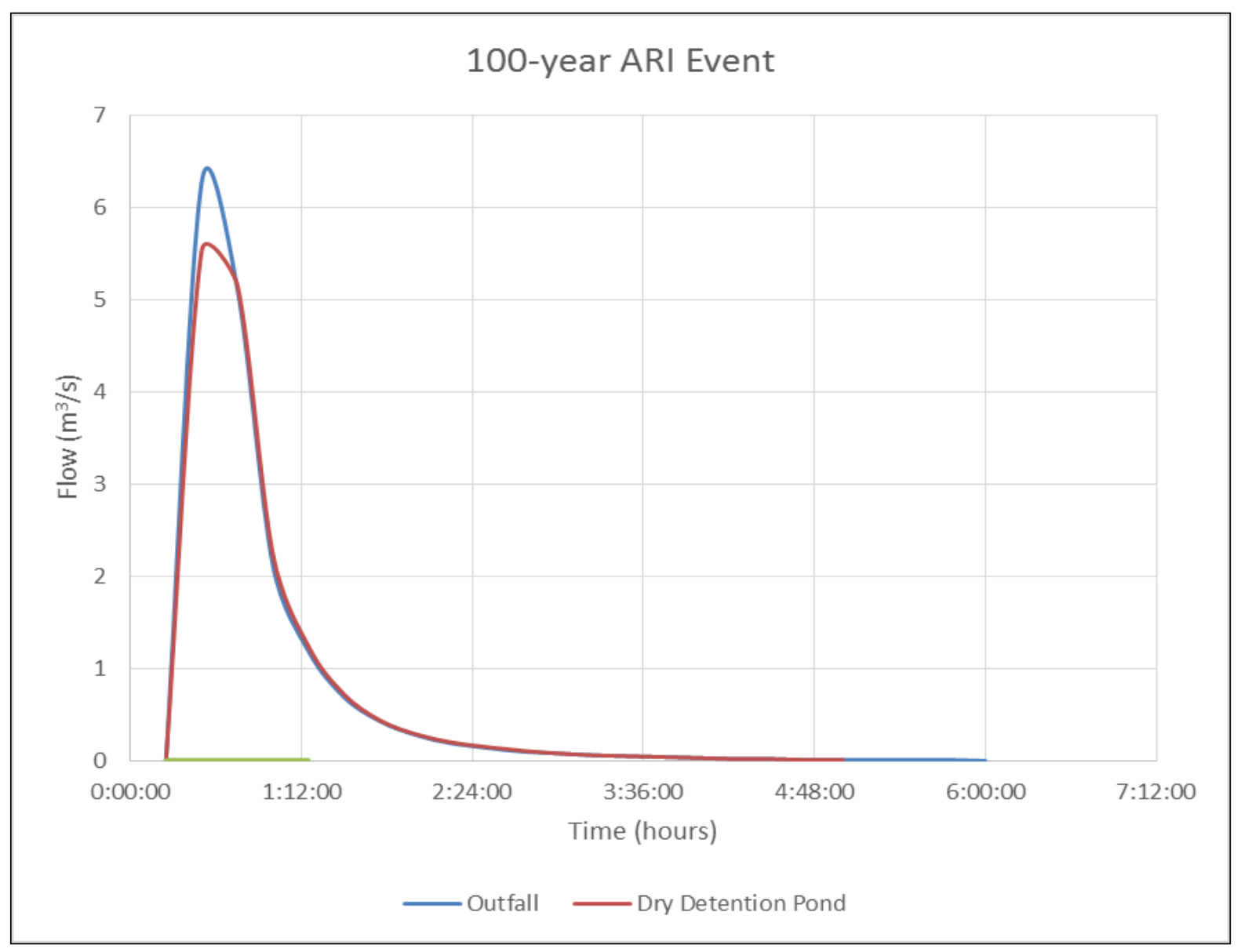

Figure 6. Comparison of Flows for 100-year Storm Event 


\section{Journal of Civil Engineering, Science and Technology}

Volume 8, Issue 1, April 2017

Based on Figure 7, the maximum depth of water stored in the dry detention pond due to a 100-year storm event is $0.67 \mathrm{~m}$. This water level is well within the design pond depth. It can be said that the remaining space of about $30 \%$ can be used as a strategy to accommodate weather variability. The weather nowadays is rather unpredictable; an extreme change in weather conditions could happen unexpectedly and this could have devastating consequences. The runoff stored within the roundabout is expected to slowly infiltrate into the ground. However, this infiltration process is not included in the modelling at the moment.

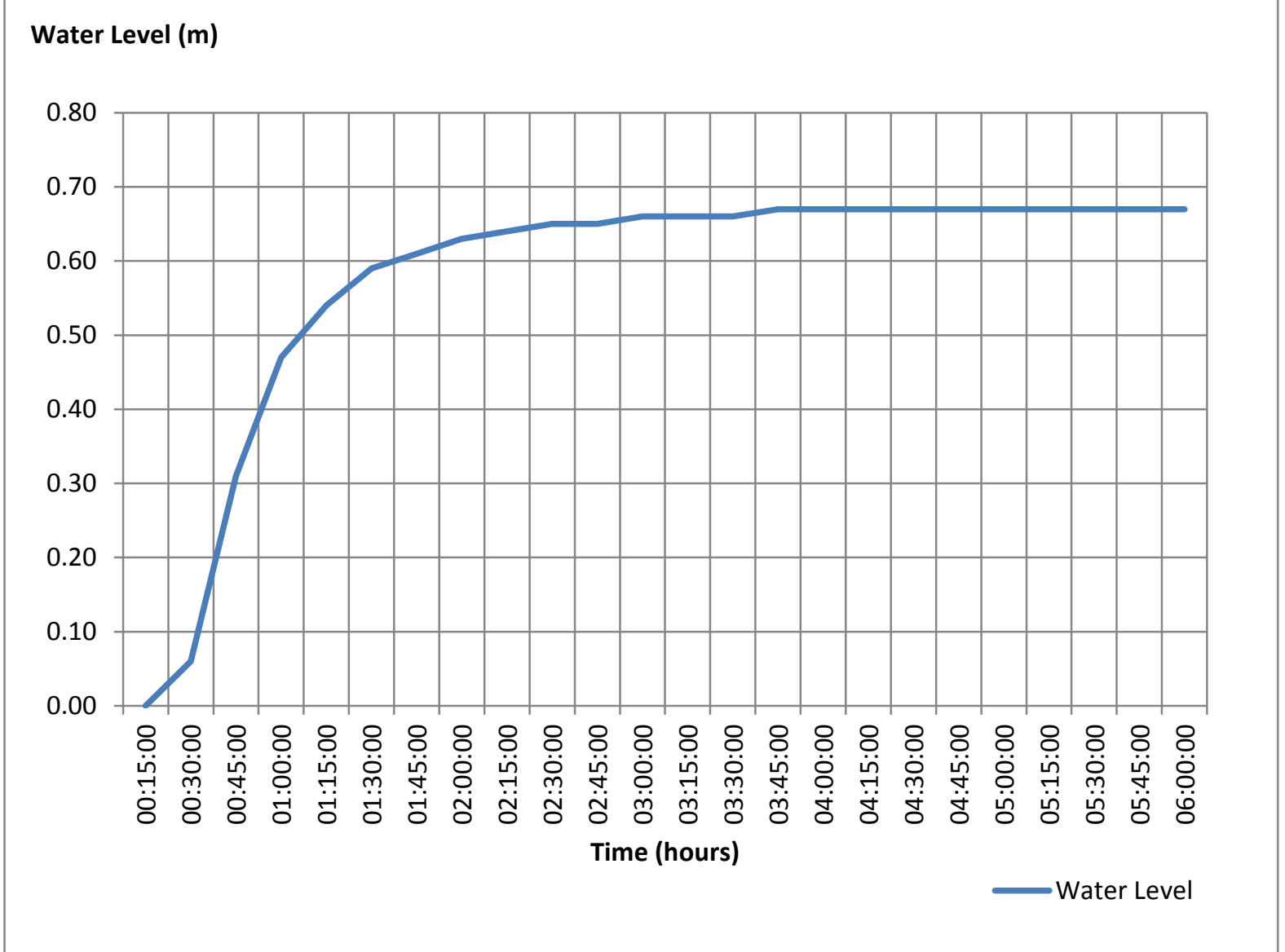

Figure 7. Filling of Roundabout Dry Detention Pond for 100-year Storm Event

\subsection{CONCLUSION}

In this paper, we have successfully developed a drainage model incorporating a roundabout as a dry detention pond, and it has been tested with computer modelling software. Based on the outcomes of computer simulation, the drainage model is workable; the proposed drainage system successfully stores $100 \%$ of surface runoff produced by a 100 -year storm event in the dry detention pond. Hence, it has been proven that a roundabout can be used as a component for flood prevention since it can provide momentary storage for runoff to attenuate surface runoff peaks. In conclusion, it is feasible for roundabout dry detention ponds to be included in the design of drainage and water management systems. The application of this concept could have positive and great impact on land use and water control schemes. 


\title{
Journal of Civil Engineering, Science and Technology
}

\author{
Volume 8, Issue 1, April 2017
}

\section{REFERENCES}

[1] B. N. Persaud, R. A. Retting, P. E. Garder, and D. Lord, 2001. Safety Effect of Roundabout Conversions in the United States: Empirical Bayes Observational Before-After Study. Transportation Research Record: Journal of the Transportation Research Board. 1751(1): 1-8.

[2] M. Băla, C. E. Toţa, C. Berar, M. Silivăşan, and A. Florişteanu, 2012. Landscape Planning Proposal for the Roundabout Cardinal Points with Ornamental Plants Suitable for Traffic. Journal of Horticulture, Forestry and Biotechnology. 16(1): 40-46.

[3] C. Wingren, 2009. Ideal Landscapes - Landscape Design between Beauty and Meaning. Nature, Space and the Sacred: Transdisciplinary Perspectives. 109.

[4] J. D. Bullough, M. S. Rea, J. D. Snyder, N. P. Skinner, R. I. Capó, P. Rizzo, and U. Besenecker, 2012. Demonstration of Roundabout Lighting based on the Ecoluminance Approach (No. 18233/C-08-03).

[5] B. Bergerot, P. Tournant, J. P. Moussus, V. M. Stevens, R. Julliard, M. Baguette, and J. C. Foltête, 2013. Coupling InterPatch Movement Models and Landscape Graph to Assess Functional Connectivity. Population Ecology. 55(1): $193-203$.

[6] D. Y. S. Mah, A. H. bin Mohamad Salehe, and F. J. Putuhena, 2014. Water Sensitive Urban Design in Existing Urban Settings: Case Study of Dry Detention Pond in Kuching City. InCIEC 2013. Singapore: Springer. pp. 315-322.

[7] Department of Irrigation and Drainage (DID), 2012. Urban Storm Water Management Manual for Malaysia or Manual Saliran Mesra Alam (MSMA), $2^{\text {nd }}$ Edition.

[8] N. A. Zakaria, A. Ab. Ghani, R. Abdullah, L. M. Sidek, A. H. Kassim, and A. Ainan, 2004. MSMA- A New Urban Stormwater Management Manual for Malaysia. $6^{\text {th }}$ International Conference on Hydroscience and Engineering (ICHE2004). Brisbane, Australia, May 30 - June 3.

[9] J. Donofrio, Y. Kuhn, K. McWalter, and M. Winsor, 2009. Water Sensitive Urban Design: An Emerging Model in Sustainable Design and Comprehensive Water-Cycle Management. Environmental Practice. 11(3): 179-189.

[10] Y. S. Liew, Z. Selamat, A. Ab. Ghani, and N. A. Zakaria, 2012. Performance of a Dry Detention Pond: Case Study of Kota Damansara, Selangor, Malaysia. Urban Water Journal. 9(2): 129-136.

[11] Y. S. Liew, F. Y. Teo, and A. Ab. Ghani, 2014. Assessment of the Climate Change Impact on a Dry Detention Pond at Kota Damansara, Malaysia. $13^{\text {th }}$ International Conference on Urban Drainage. Kuching, Sarawak, Malaysia, 7 - 12 September.

[12] N. A. Zakaria, and C. K. Chang, 2014. Application of Greener Technology - Sustainable Use of Natural Resources in Urban Stormwater Management. International Federation of Landscape Architects (IFLA) 2014 Asia Pacific Congress. Kuching, Sarawak, 28 - 30 April.

[13] S. H. Lai, and D. Y. S. Mah, 2012. Field Investigation of a Dry Detention Pond with Underground Detention Storage. Hydrological Sciences Journal. 57(6): 1249-1255.

[14] S. Beecham, 2011. Using Water Sensitive Urban Design to Achieve Multi-Functional Urban Landuse. Stormwater Industry Association of Queensland State Conference 2011. Queensland, Australia, 25 - 27 May.

[15] Susdrain, 2012. Dunfermline Eastern Expansion, Scotland. Available from http://www.susdrain.org/casestudies/case_studies/dunfermline_eastern_expansi on_scotland.html\#_(accessed 17 March 2015).

[16] K. Lee, H. Kim, G. Pak, S. Jang, L. Kim, C. Yoo, Z. Yun, and J. Yoon, 2010. Cost-Effectiveness Analysis of Stormwater Best Management Practices (BMPs) in Urban Watersheds. Desalination and Water Treatment. 19(1-3): 9296. 